\title{
Stigma during the COVID-19 pandemic: Important but overlooked
}

\author{
Arsia Taghva ${ }^{1}$, Leila Gonabadi Nezhad ${ }^{2}$ \\ 1-Professor, Department of Psychiatry, Aja University of Medical Sciences, Tehran, Iran. \\ 2- Military Psychiatric Flow, Department of Psychiatry, Aja University of Medical Sciences, Tehran, Iran \\ (Corresponding Author). \\ E-mail: Gonabadi_1@yahoo.com
}

Received: 29/08/2021

Accepted: 08/12/2021

\begin{abstract}
COVID-19 was declared a pandemic in march 2020 and has became a top priority for governments and health systems worldwide. The disease has severe consequences in terms of morbidity and mortality, significant economic impact and far-reaching social and cultural changes. These findings have led to increased efforts to study the disease, treat it, and respond to the economic consequences of the pandemic. However, the psychological consequences of the disease, including the widespread COVID -19 stigma, have been overlooked. COVID-19-related stigma threatens various groups, including patients, survivors, health care professionals, and other at-risk populations. The possibility of person-to-person transmission, high levels of ignorance about the disease, fear of ambiguity and lack of knowledge, and constant changes in relevant regulations and recommendations lead to the COVID -19 stigma. Stigmatization has many negative consequences: concealment of the disease, delay in seeking health services, refusal of preventive measures, stress, and related socioeconomic consequences. Therefore, the necessary measures in this regard should be considered. In particular, the spread of stigma should be prevented through measures to raise awareness and ensure access to reliable information.
\end{abstract}

Keywords: Social stigma, COVID-19, Psychological disorders, Health behaviors

How to cite this article: Taghva A, Gonabadi Nezhad L. Stigma during the COVID-19 pandemic: Important but overlooked. Shenakht Journal of Psychology and Psychiatry. 2022; 8 (6): 50-55 .URL: http://shenakht.muk.ac.ir/article-1-1258-en.pdf

Copyright ( 2018 the Author (s). Published by Kurdistan University of Medical Sciences. This is an open access article distributed under the terms of the Creative Commons Attribution-Non Commercial License 4.0 (CCBY-NC), where it is permissible to download, share, remix, transform, and buildup the work provided it is properly cited. The work cannot be used commercially without permission from the journal. 


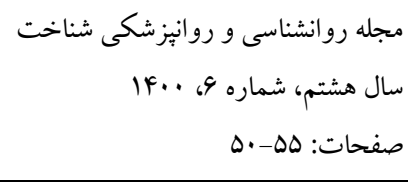

\title{
نامه به سردير استيكما در جريان همدكيرى كوويد-19: مهم اما مغفول
}

\author{
ارسيا تقوا'، ليلا كنابادى نزاد'

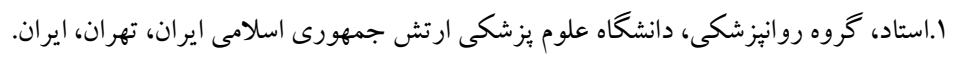

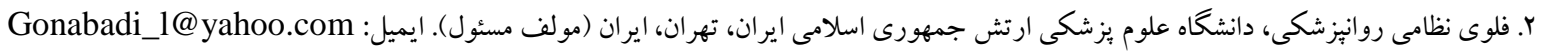 \\ تاريخ بذيرش مقاله: |F.../.9/VV \\ تاريخ دريافت مقاله: |
}

جكيده

بيمارى كوويد-19 در سال ·r.r.r به عنوان يك بِاندمى اعلام گرديد و به اصلىترين اولويت حكومتها و سيستمهاى بهداشتى و

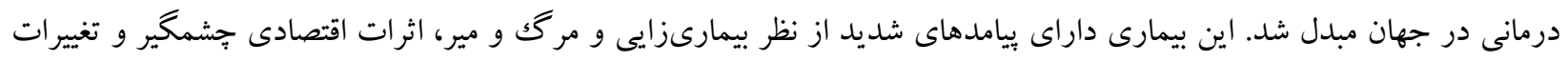

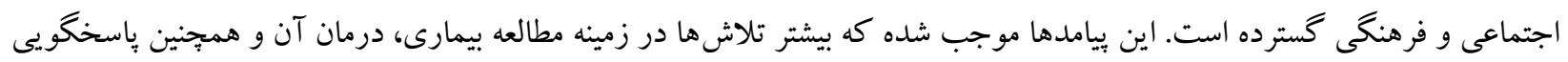

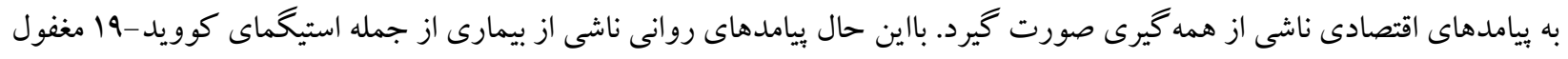

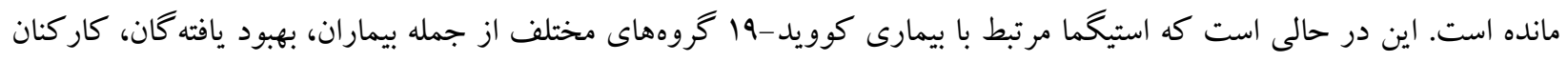

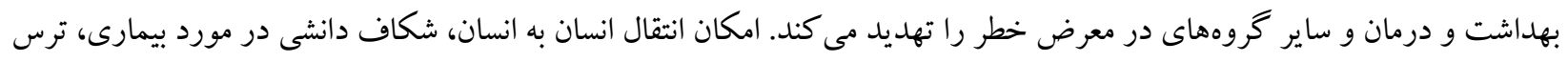

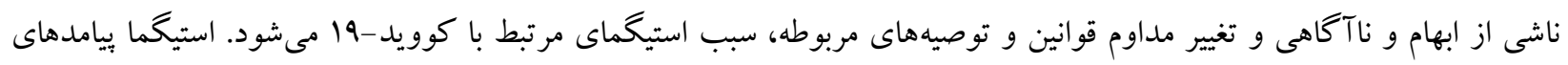

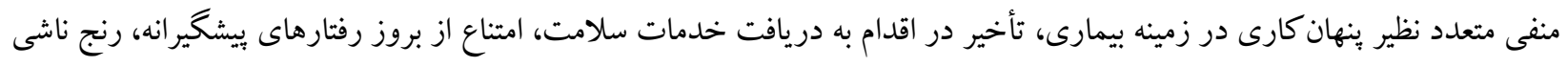

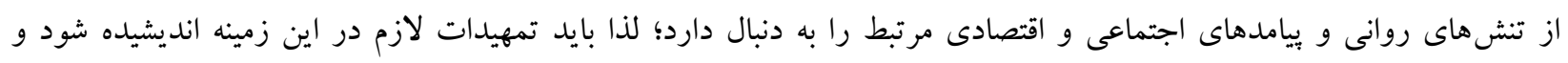
بخصوص از طريق اقداماتى در راستاى آكاهىبخشى و تضمين دسترسى به اطلاعات موثق، از شيوع استيخما بيشخيرى شود. كليدوازهها: استيخماى اجتماعى، كوويد-919، اختلالات روانى، رفتار سلامتمدار 
DYVVMYV

$(r \cdot Y)$

بهصورت تاريخى مفهوم استيخمال (در فارسى انگك) در يونان باستان و بهمنظور علامت گذارى افراد مثلاً به عنوان جنايتكار، خائن و يا برده مورد استفاده قرار مى گرفت. بعدها براى اولين بار در سال سو19 اين وازه توسط

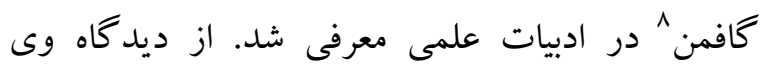

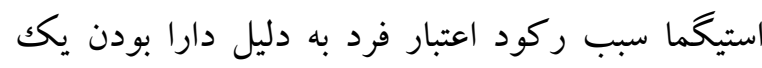
صفت و يا مشخصه خاص مىشود (باتس و استيكلى'،

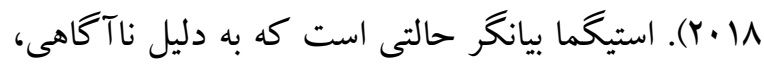
بيشداورى و تبعيض رفتارى، نسبت به يك بديده نمود مى يابد؛ بنابر اين در شكل گيرى استيخما نآكاهى و جهل

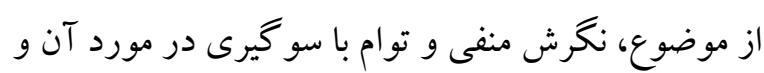
سبس اقدام برآمده از تبعيض و نخرش نادرست دخيل

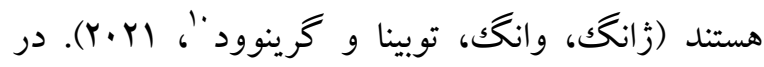
فر آيند اطلاق انگك به يك فرد در حقيقت وى به خاطر ويز گیىهايى كه غالباً سبب تمايز فرد با فرد يا افراد انگك كذار مىشود، از گروه جداو وممكن است مزاياى حضور در اجتماع از وى سلب شود. اين شرايط سبب ايجاد ترس، خشم و اضطراب از مواجهه با سايرين مىشود. همجنين اعتماد به نفس فرد كاهش مي يابد، احساس شرم مى كند و در نتيجه شرايط اجتماعى - اقتصادى (بيكارى و عدم ايفاى نقش اجتماعى) وى به دليل بيامدهاى استيخما رو به وخامت خواهد رفت (رينكا، بان-ويز، لاونر و

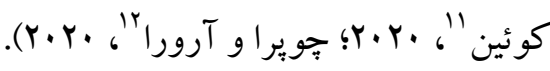

7- Stigma

8 - Goffman

9- Bates \& Stickley

${ }^{10}$ - Zhang, Wang, Toubiana \& Greenwood

${ }^{11}$ - Reinka, Pan Weisz, Lawner \& Quinn

${ }^{12}$ - Chopra \& Arora
با سلام و احتر ام

سردبير محترم مجله روانشناسى و روانيزشكى شناخت بيمارى كوويد-19' به عنوان سندرم تنفسى حاد كرونا

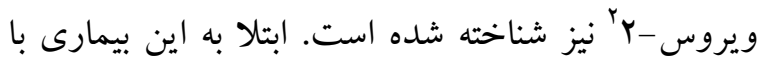
مشكلات عديده و جدى در دستگاه تنفس فوقانى همراه است و انتقال آن از طريق هوا و به وسيله سرفه و عطسه ممكن مىشود. همجين اين بيمارى از طريق ارتباط فيزيكى و يا نزديكى به فرد مبتلا و لمس اشياء و سطوح

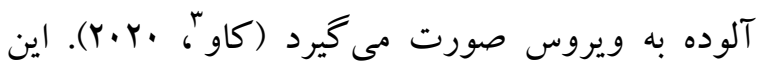
ويروس براى اولين بار در ماه دسامبر سال 19 •r در شهر ووهان ج جين و بعد از مطالعه و بررسى بر ب نمونه با علائم بنومونى و با سببشناسى ناشناخته، شناسايى گرديد (نيرو،

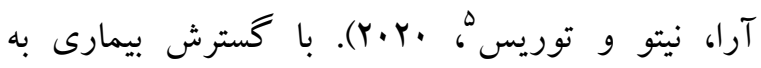

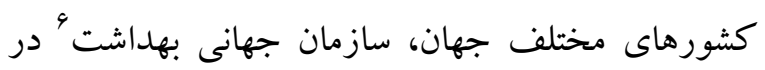

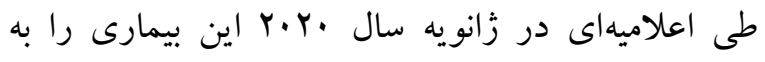
عنوان يك اضطرار سلامت عمومى اطلاعرسانى كرد و سبس همه گيرى جهانى آن در مارس سال .Y.Y.T توسط

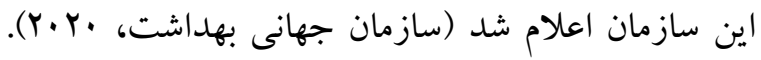
در ايران نيز اولين مورد از ابتلا به اين بيمارى در شهر قم

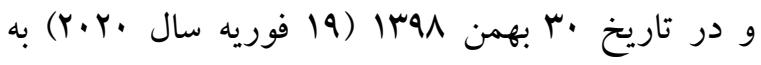
صورت رسمى اطلاعرسانى شد (قره باغى و حيدرى، 9 (1). براساس آخرين آمار اعلامى سازمان جهانى بهداشت، در مورخ W 1 آذرماه .. IF (9 دسامبر سال (Y.Y. تعداد موارد تشخيص قطعى ابتلا به كوويد-19 و و (19) فوت ناشى از آن به ترتيب برابر با س YRIAFGY و

1. COVID-19

2- SARS-Cov-2

3 - Cao

4- Wuhan

5 - Ndarrou, Area, Nieto \& Torres

${ }^{6}$ - World Health Organization (WHO) 
انديشمندان از آن به عنوان رويداد (قوهاى سياه)" ياد

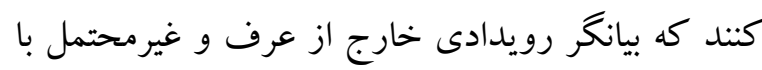
تأثيرات شخرف و وسيع است؛ لذا اين عدم قطعيت و نآكاهى در مورد بيمارى سبب ايجاد ترس و نكرانى

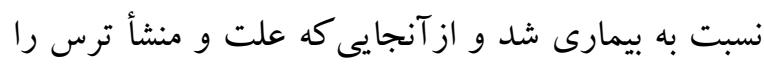
به راحتى مى توان به سايرين نسبت داد؛ لذا شيوع استيخما در اين زمينه تسهيل مىشود (كروور، سينگك، ساهوو و وإنى

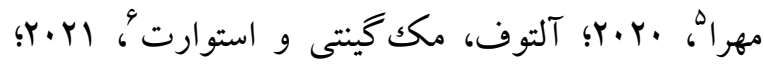

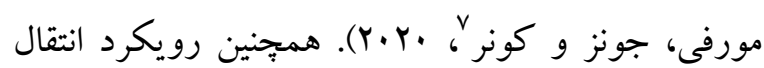
بيمارى از فردى به فرد ديخر و عدم اطمينان و تغيير مداوم در قوانين و توصيه هاى مرتبط با اين بيمارى سبب تشديد احتمال استيخماى كوويد-19 شده است (آلتوف و و همكاران، (Y.Y.Y). در اين شرايط احتمال انگك گذارى بر كروههاى مختلف افراد نظير بيماران مبتلا، افراد بهبود يافته، كاركنان بهداشت و درمان، گروههاى برخطر نظير

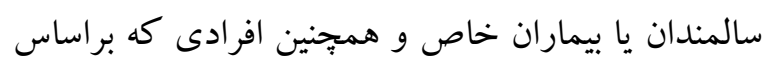
مؤلفههايى نظير نزاد، منطقه جغرافيايى و ساير مؤلفهها

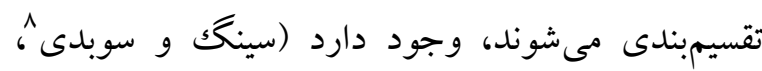

\section{.$(Y \cdot Y$.}

استيخماى كوويد-19 بيامدهاى نامطلوب متعددى به همراه دارد. در مورد افراد مبتلا احتمال ينهان كردن بيمارى افزايش مى يابد، تمايل فرد براى بيخيرى بيمارى و

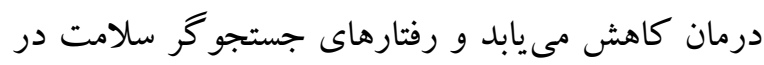
وى تضعيف مىشود. همجِين اختلالات روانشناختى متعددى نظير استرس، اضطراب و فرسودگى در نتيجه اين شرايط حاصل مىشود كه منجر به تأثير سوء بر كيفيت

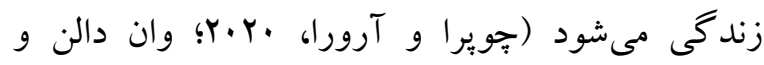

در مورد بيمارىها استيخما به شرايطى اطلاق مى گردد كه در آن فرد به دليل ابتلا به يكك بيمارى از سايرين تميز داده شده و روابط اجتماعى وى تحتالشعاع قرار

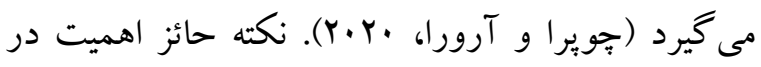
مورد استيخماى مرتبط با بيمارى آن است كه استيخما

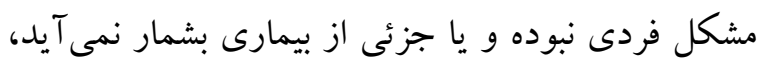

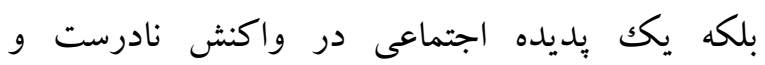
تبعيض آميز نسبت به فرد مبتلا است (رينكا و همكاران، .Y.Y. كوويد-19 است كه به يكى از جالشهاى مديريت

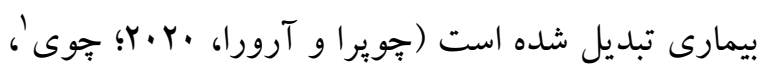

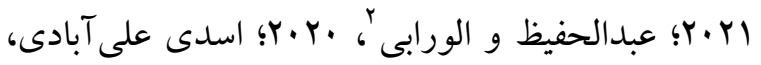
تهرانى بنىهاشمى و مرادى لاكه، وهبا؛ بدرفام و

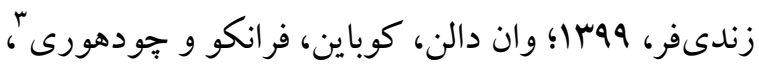

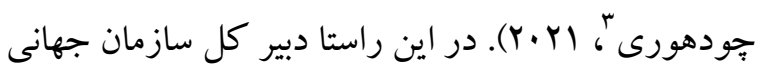
جهانى بهداشت اظهار داشته است كه \بزر گترين دشمن ما ويروس نيست، بلكه ترس، شايعات و استيخماى مرتبط

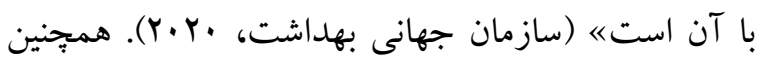
وان دالن و همكاران (Y.Y.Y) از استيگما به عنوان يكك ويروس اجتماعى ياد كردهاند كه سريعتر از كوويد-19

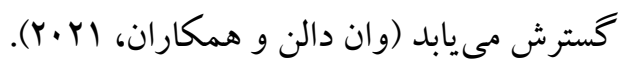
دلايل استيخماى كوويد-19 را مىتوان در ماهيت

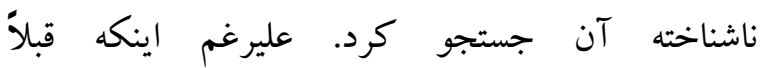
بيشبينىهايى در مورد احتمال شيوع بيمارىهاى ويروسى صورت گرفته بود، باينحال شيوع يكباره و كسترده اين بيمارى به همراه بيامدهاى شخرف تمامى حوزههاى زندگى بشر سبب شد كه حتى برخى از

\footnotetext{
1- Choi

2. Abdelhafiz \& Alorabi

3. Van Daalen, Cobain, Franco \& Chowdhury
}

4- Blak swans

- Grover, Singh, Sahoo \& Mehra

- Althoff, Mcginty \& Stuart

- ${ }^{\text {- Murphy, Jones \& } \& \text { Subedi }}$ 
شود. راهكارها بايد بر اساس علل ريشهاى اين عارضه ارائه شود. در اين راستا به دليل ماهيت ذهنى استيگما، بايد زمينه براى تغيير نكرش ناشى از آكاهى ناكافى و ولى

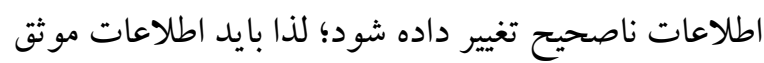
در اختيار افراد قرار گيرد و از ارائه اطلاعات غير ضرورى ديح و نادرست اجتناب شود، آموزش و اطلاعرسانى عمومى به منظور تقويت تابآورى و توان مقابلهاى آنان انجام شود و رفتارهاى صحيح در اجتماع مورد تشويق و تائيد قرار گيرد. در زمينه آموزش و فرهنگكسازى مىتوان از يتانسيلهايى نظير رسانهاى عمومى، افراد صاحب نفوذ اجتماعى نظير بزر گان علمى و مذهبى و همجينين شخصيت هاى بنام هنرى و ورزشى استفاده نمود. همجينين جريان اطلاعات و انتشار آن بايد به صورت جدى و وركئ موشكافانه رصد شود. به نظر مىرسد اطلاعات آيندهنگ با بازه طولانى در مورد احتمال كنترل بيمارى و يا فراهمى واكسن مربوطه، ممكن است ذهنيت تداوم و استمرار بيمارى را ايجاد نموده و بر ترس افراد بيفزايد.

\section{References}

Abdelhafiz AS, Alorabi M. (2020). Social stigma: the hidden threat of COVID-19. Frontiers in Public Health. 8, 429.

Althoff K, Mcginty B, StuartE. (2021). COVID-19 and Stigma: Why shame and blame won't help fight the pandemic, and what we should be focusing on instead. School of Public Health Expert Insights, JOHNS HOPKINS Available online: https://wwwjhsphedu/covid19/articles/covid19-and-stigmahtml. 2021.

Asadi-Aliabadi M, Tehrani-Banihashemi A, MoradiLakeh M. (2020). Stigma in COVID-19: A barrier to seek medical care and family support. Medical Journal of the Islamic Republic of Iran. 34, 98. (In Persian)

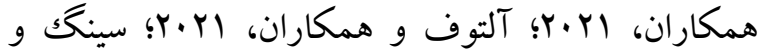

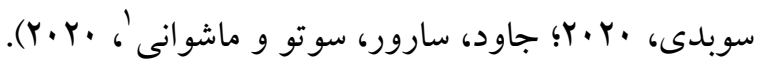

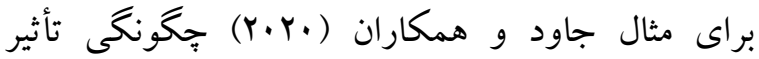
استيخماى كوويد-19 بر مؤلفهاى سلامت روانى را مان تشريح كردهاند (جاود و همكاران، ·Y.Y.Y). همجنين در

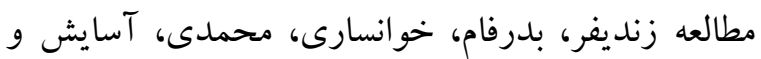
قربانى (9941) همبستخى استيخماى كوويد-19 با اختلال

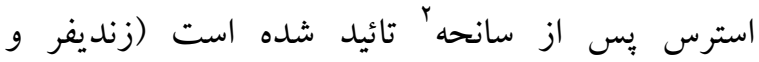
همكاران، 99 1). تداوم اين شرايط در سطح كلان، مديريت بيمارى را دشوار مى كند و بيامدهاى اقتصادى و اجتماعى گسترده و مخربى به دنبال دارد (جويرا و آرورا،

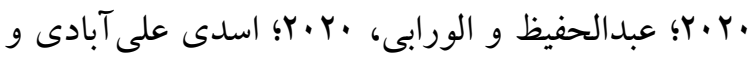

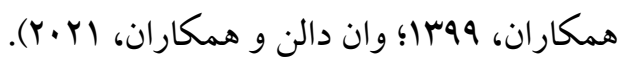
همه گيرى كوويد-19 بيامدهاى منفى متعددى به دنبال داشته است كه نياز به تصميم گيرى قاطع و بهنگام براى مقابله با آنها وجود دارد. در اين راستا تاكنون اغلب تلاشها در زمينه مطالعه بيمارى و رويكردهاى درمانى آن، دستيابى به واكسن مؤثر و ايمن و جبران ييامدهاى منفى كسترده اقتصادى بيمارى بوده و كمتر توجهى به به ييامدهاى روانشناختى ناشى از آن شده است. استيخماى

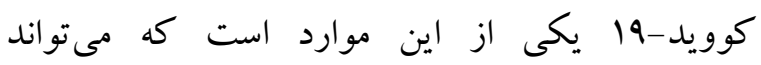
كروههاى مختلف را تحت تأثير قرار دهد، عواقب ناگوار فردى و اجتماعى به دنبال داشته باشد و اثربخشى اقدامات صورت گرفته در زمينه مديريت بيمارى را كاهش دهد. اين شرايط لزوم بررسى وضعيت موجود، تدبير در شرايط بهنظور تبيين راهبردهاى ممكن و ارائه راهكارها و و سناريوهاى محتمل را الزامى مى كند تا از اين طريق شرايط براى بيشخيرى از استيخما و عوارض آن فراهم

1- Javed, Sarwer, Soto \& Mashwani

2 - Post-traumatic Stress Disorder 
Badrfam R, Zandifar A. (2020). Stigma over COVID19; new conception beyond individual sense. Archives of Medical Research. 51, 593-594. (In Persian)

Bates L, Stickley T. (2018). Confronting Goffman: How Can Mental Health Nurses Effectively Challenge Stigma? A Critical View of the Literature. European Psychiatric/Mental Health Nursing in the 21st Century. 493-503.

Cao X. (2020). COVID-19: immunopathology and its implications for therapy. Nature Reviews Immunology. 20(5), 269-270.

Choi S. (2021). "People look at me like I AM the virus": Fear, stigma, and discrimination during the COVID-19 pandemic. Qualitative Social Work. 20(1-2), 233-239.

Chopra K, Arora V. (2020). Covid-19 and social stigma: Role of scientific community. The Indian Joumal of Tuberculosis. 284-285.

Gharebaghi R, Heidary F. (2020). COVID-19 and Iran: swimming with hands tied! Swiss medical weekly, 150(1516). (In Persian)

Grover S, Singh P, Sahoo S, Mehra A. (2020). Stigma related to COVID-19 infection: Are the Health Care Workers stigmatizing their own colleagues? Asian Journal of Psychiatry. 53, 102381.

Javed B, Sarwer A, Soto EB, Mashwani ZuR. (2020). The coronavirus (COVID-19) pandemic's impact on mental health. The International Journal of Health Planning and Management. 35(5), 993-996.

Murphy JF, Jones J, Conner J. (2020). The COVID-19 pandemic: Is it a "Black Swan'? Some risk management challenges in common with chemical process safety. Process Safety Progress. 39(2), e12160.

Ndairou F, Area I, Nieto JJ, Tomes DF. (2020). Mathematical modeling of COVID-19 transmission dynamics with a case study of Wuhan. Chaos, Solitons \& Fractals. 135, 109846.

Reinka MA, Pan-Weisz B, Lawner EK, Quinn DM. (2020). Cumulative consequences of stigma: Possessing multiple concealable stigmatized identities is associated with worse quality of life. Journal of Applied Social Psychology. 50(4), 253-261.

Singh R, Subedi M. (2020). COVID-19 and stigma: Social discrimination towards frontline healthcare providers and COVID-19 recovered patients in Nepal. Asian Joumal of Psychiatry. 53, 102222.

Van Daalen KR, Cobain M, Franco OH, Chowdhury R. (2021). Stigma: the social vinus spreading faster than COVID-19. 75(4), 313-314.

World Health Organization (WHO), speeches. (2020). Available online: https://www.who.int/dg/speeches/detail/whodirector-general-s-opening-remarks-at-themedia-briefing-on-covid-19 -28-february2020. (accessed on 28February 2020).

World Health Organization (WHO). (2020). COVID19 Public Health Emergency of Intemational Concem (PHEIC) Global research and innovation forum. Available online:https://www.who.int/publications/m/ite $\mathrm{m} /$ covid-19-public-health-emergency-ofintemational-concem-(pheic)-global-researchand-innovation-forum. (accessed on 12 February 2020).

World Health Organization (WHO). (2021). WHO Coronavirus (COVID-19) Dashboard. Available online: https://covid19.who.int/. (accessed on 9December 2021).

Zandifar A, Badrfam R, Khonsari NM, Mohammadi MR, Asayesh H, Qorbani M. (2020). Prevalence and associated factors of posttraumatic stress symptoms and stigma among health care workers in contact with COVID-19 patients. Iranian Journal of Psychiatry, 15(4), 340. (In Persian)

Zhang R, Wang MS, Toubiana M, Greenwood R. (2021). Stigma Beyond Levels: Advancing Research on Stigmatization. Academy of Management Annals. 15(1), 188-222. 